\title{
THE EFFECT OF SOCIAL SECURITY ON EARLY RETIREMENT
}

\author{
Michael J. BOSKIN and Michael D. HURD* \\ National Bureau of Economic Research, Stanford, C.4 94305, L.S.A.
}

Received September 1977, revised version received August 1978

\section{Introduction}

Despite the improved health, shift out of physically dangerous or demanding jobs and increased life expectancy of the elderly population of the United States, their labor force participation rates have declined rapidly in the past two decades. The first three columns of table 1 document this phenomenon; the decline was approximately $6 \%, 18 \%$ and $40 \%$ for men aged $55-59,60-$ 64 and $65+$ respectively in the period 1957-74. Many factors potentially contributed to this decline: the growth of income combined with a nontrivial income elasticity of demand for leisure; technological change; and the rapid growth of social insurance programs come immediately to mind.

This decline in the labor force participation of the elderly population is of much more than purely historical interest. It has a variety of implications for the welfare of the elderly, and the general population. These include the usual types of labor market distortions, the strain on the financial resources of the elderly as the average number of years from retirement to death increases rapidly, the often suggested positive correlation between physical and psychological problems and labor force withdrawal and the sharp increase in the funding of public programs supporting the elderly.

Our purpose in the present study is to analyze a new and rich body of data on the elderly to study the supply side of the effect of social security on the early retirement decision. Toward this end, section 2 presents a brief description of some previous studies of retirement behavior. While each in its own way has been suggestive, each also (including one by one of the current authors) has its own set of problems.

Section 3 details the analytical framework of the present study. We propose several types of data from which one could obtain complementary

*We wish to thank Takeshi Amemiya for valuable comments; Henry Moore, Louis Garrison and William Barsky for research assistance; and the Office of Income Security Policy. HEW, and the American Enterprise Institute for financial support. 
Table 1

Elderly male labor force participation rates and early acceptance of social security rates.

\begin{tabular}{|c|c|c|c|c|}
\hline \multirow[b]{2}{*}{ Year } & \multicolumn{3}{|c|}{$\begin{array}{l}\text { Labor force participation rate } \\
\text { (by age group) }\end{array}$} & \multirow{2}{*}{$\begin{array}{l}\text { Percent accepting } \\
\text { benefits age } 62-64\end{array}$} \\
\hline & $55-59$ & $60-64$ & $65+a$ & \\
\hline 1957 & 91.5 & 82.9 & 37.7 & N.A. \\
\hline 1958 & 91.8 & 83.2 & 35.7 & N.A. \\
\hline 1959 & 91.3 & 82.3 & 34.3 & N.A. \\
\hline 1960 & 91.6 & 81.1 & 33.3 & N.A. \\
\hline 1961 & 91.8 & 81.9 & 31.9 & 20 \\
\hline 1962 & 91.1 & 80.3 & 30.6 & 29 \\
\hline 1963 & 91.3 & 80.1 & 28.4 & 31 \\
\hline 1964 & 91.1 & 79.1 & 27.9 & 32 \\
\hline 1965 & 90.2 & 78.0 & 27.9 & 32 \\
\hline 1966 & 90.0 & 78.0 & 27.2 & 32 \\
\hline 1967 & 90.1 & 77.6 & 27.1 & 33 \\
\hline 1968 & 90.0 & 77.3 & 27.3 & 33 \\
\hline 1969 & 89.6 & 75.8 & 27.3 & 34 \\
\hline 1970 & 89.5 & 75.0 & 26.7 & 36 \\
\hline 1971 & 88.8 & 74.1 & 25.6 & 39 \\
\hline 1972 & 87.4 & 72.5 & 24.4 & 41 \\
\hline 1973 & 86.5 & 69.0 & 22.8 & 44 \\
\hline 1974 & 85.7 & 67.9 & 22.5 & 46 \\
\hline
\end{tabular}

"Whites only.

Source: U.S. Bureau of Labor Statistics and H.E.W.

information on the labor supply behavior of the elderly, and three approaches to analyzing a given body of data. We then propose a new way of estimating retirement behavior.

Section 4 discusses the data used in this study: the Social Security Administration's Retirement History Survey.

Section 5 reports our empirical results, estimates of probability of early retirement and early semiretirement equations.

Section 6 concludes with a brief discussion of some of the implications of the study and suggestions for future research.

\section{Previous studies}

Social security guarantees elderly retired persons a certain income based upon their previous covered earnings and taxes some of these benefits back if earnings exceed a modest amount. Theory tells us little about the overall effect of social security on retirement; rather it is an empirical issue for at least three reasons: some workers choose to work enough so that they receive no payments from social security; some people would retire regard- 
less of their social security benefits; the effect of changes in the system on workers who receive benefits is not known. We need to know the distribution of people among the three categories and how the distribution changes when the system changes.

Previous studies of retirement or the labor force participation rates of the elderly differ in their conclusions on the effect of social security on retirement behavior. Retrospective studies of retired workers generally conclude that the bulk of retirement was due to poor health. While it is undoubtedly correct that some people retire because of poor health, accepting the conclusion that most do so from retrospective surveys is hazardous: poor health is certainly the most socially acceptable reason for retirement, and the health of those interviewed had, on average, deteriorated since retirement.

Econometric studies of elderly male labor force participation rates across countries have concluded that social security benefit increases induce retirement [see Pechman, Aaron and Taussig (1968) and Feldstein (1974)]; the same conclusion is reached by Boskin, who followed the labor force behavior of a cohort of elderly males for five years. These studies are discussed and critiqued in greater detail in Boskin.

\section{Analytical framework and estimation methods}

Our model is a modification of the usual static, two-good, labor supply under certainty case. While we conceive of the problem under investigation as potentially embedded in a life-cycle and/or uncertainty context, we believe that important progress empirically can best be made at present by a more careful analysis of the usual model. Thus, we want to study changes between three states: working, semiretirement, and retirement. We define these states to be working but not receiving social security payments, working but receiving social security payments, and not working respectively. Obviously, some people may reduce their hours of work as they age, yet always have labor incomes that disqualify them from receiving any social security payments. It is not our focus, however, to investigate how hours of work change with age; rather, we are interested in how the social security system influences behavior, and small variations in the benefit structure will not change the behavior of people who never receive social security payments. Our goal is to estimate the determinants of the probabilities of people moving among several states. The probabilities are moving from working to retirement and from working to semiretirement. We describe the process in the following way: at age 62 the budget constraint of a worker is changed in a way that is partly exogenous and partly endogenous: the fact that the constraint changes is exogenous in that it only depends on the age of the worker, but the size of the change is endogenous because the benefit depends on the past earnings history of the worker, and that history is a reflection of 
the tastes for work of the worker. In the face of the new budget constraint, the worker will, on average, maximize utility by choosing one of the three states we have defined. We hope to find, for example, how the probability of leaving the state of working for the state of retirement varies when the benefit level varies, and, therefore, how changes in the benefit levels will change the working behavior of the elderly population.

The budget constraint of someone of retirement age is given in fig. 1. In

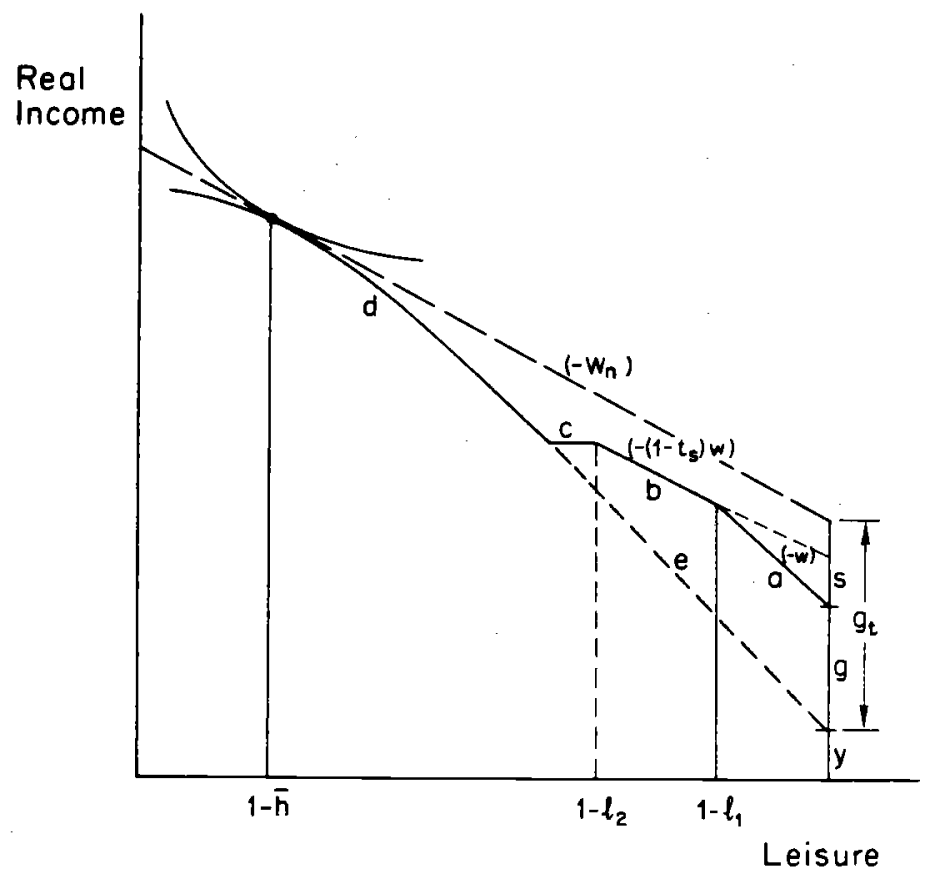

Fig. 1. Social security and the budget constraint of the worker (see text for discussion).

the absence of social security, this worker would have nonlabor income of $y$ and a budget constraint given by the segments $d$ and $e$. This preretirement budget constraint is curved to reflect the progressivity of the federal income tax. The worker maximizes utility by working $\hbar$ hours. Upon reaching potential eligibility age the right side of the budget constraint is altered so that it is now given by the segments $y, \mathrm{~g}, a, b, c$ and $d .^{1} \mathrm{~g}$ is the benefit level; over segment $a$ earnings are not taxed; over segment $b$ earnings are taxed at

${ }^{1}$ A slight increase in monthly benefits is granted for each month past age 62 , but before age 65 , that benefits commence. Since elderly, especially low income, households appear to discount at rates [Kurz, et al. (1974)] perhaps ten times the $3 \%$ that renders the present value of benefits independent of retirement age, we ignore this effect. 
the statutory 50 percent rate; over segment $c$ earnings are taxed at a 100 percent rate; over segment $d$ no social security payment is made.

There are at least three approaches to the estimation of the probabilities of movement from one part of the budget constraint to another. In the first, one specifies a utility function and a distribution of the random component of tastes. Estimation of the parameters of the utility function and the parameters of the distribution of the taste component would lead to knowledge of how the probabilities change when the budget constraint changes. For many problems this is a useful way to proceed, especially if one wants to make welfare comparisons. Because we do not want to make welfare comparisons and we do not have any strong opinion on the form of the utility function, we do not follow this approach.

In the second approach, one specifies an hours of work function and the distribution of the random component in hours of work. If that function and distribution were known, one could calculate the probability that hours of work would be chosen along each segment of the budget constraint, and how that probability would vary with changes in the constraint. When the budget constraint is convex from above, this approach is quite straightforward: the parameters of both the labor supply function and the distribution of the random component may be estimated by maximum likelihood once it is recognized that the wage rate is chosen by the worker according to the segment of the budget constraint he chooses. If, for example, the random component has a normal distribution, the distribution of hours along segment $a$ is truncated normal. Similarly, the likelihood of the cluster of hours one would expect at the kink between segments $a$ and $b$ can be specified quite easily. These likelihoods are easy to specify because they only depend on the slope and intercept of one (or at most two) segment. When the budget constraint is concave from above, the situation is quite different. The likelihood that an observation will lie along, say, segment $b$ depends not only on its slope and intercept, but also on the position of segment $d$. The probability that hours of work lie at a certain point of segment $b$ depends on the slope and intercept of $b$ and on the probability that utility is higher along $b$ than along $d$. In the absence of a utility function it is not easy to specify what that probability is; hence, it is difficult to specify the likelihood of the sample.

In our approach we estimate directly the probabilities of each change of state. The probabilities are related to the slopes and intercepts of the segments through the indirect utility function. Let $t_{s}$ be the tax rate of earnings of those who are receiving social security payments; $w$ be the gross wage rate which we take to be exogenous; $g$ be the social security benefit; $y$ be nonlabor income which in our data will be composed of dividends and interest and imputed returns to other assets and debts; $t$ be the marginal income tax rate; $W R$ be the event of moving from working to retirement. 
Then,

$$
\begin{aligned}
P(W R)= & P\left(V\left(w_{n}, y+g_{1}, u\right)<U(0, g+y, u)\right. \text { and } \\
& U(0, g+y, u)>\max \text { utility from semiretirement }),
\end{aligned}
$$

where $V$ is the indirect utility function, $U$ is the direct utility function, $w_{n}$ $=w(1-t)$ and $u$ is a random component resulting from maximization errors and differences in tastes for work in the population. Direct utility is defined over the leisure of the husband (the leisure of the wife does not enter because our subsample does not include any wives who work), an index of real income which is calculated as money income plus imputed income divided by a price index derived from geographical information, and the random component. Indirect utility is the maximum utility that could be achieved if the budget constraint were linear with wage $w_{n}$ and nonlabor income $y+g_{t}$. $g_{t}$ is that nonlabor income which would have to be offered in order that a person with nonlabor income $y$ and a constant wage $w_{n}$ would choose hours of work $\bar{h} . g_{t}$ may be calculated as $t \bar{h}_{w}-T$, where $T$ is the actual income tax paid. The inequalities say that utility at the point chosen before the modification of the budget constraint (the point, where utility is the greatest achievable along $d$ ) is less than the utility of retirement and that the utility of retirement is greater than the utility of semiretirement. The maximum utility from semiretirement is

$$
\begin{aligned}
& V(w, g+y, u) \quad \text { if } l(w, g+y, u)<l_{1}, \\
& U\left(l_{1}, g+y+w l_{1}, u\right) \quad \text { if } \quad l\left(\left(1-t_{s}\right) w, y+g+s, u\right) \\
& \quad<l_{1}<l(w, g+y, u), \\
& V\left(\left(1-t_{s}\right) w, y+g+s, u\right) \quad \text { if } \quad l_{1}<l\left(\left(1-t_{s}\right) w, y+g+s, u\right)<l_{2}, \\
& U\left(l_{2},\left(1-t_{s}\right) w l_{2}+y+g+s, u\right) \quad \text { if } \quad l_{2}<l\left(\left(1-t_{s}\right) w, y+g+s, u\right),
\end{aligned}
$$

where $l$ is the labor supply function and $l_{1}$ and $l_{2}$ are the hours of work that correspond to the breakpoints in the budget constraints. The four inequalities give the conditions under which, respectively, utility will be maximum along $a$, at the breakpoint between $a$ and $b$, along $b$, and at the breakpoint between $b$ and $c$. Because $l_{1}$ depends on the maximum allowable earnings before income is taxed and upon $w$ and $g+y$, conditions involving $l_{1}$ may be reduced to conditions on $w$ and $g+y$ : the upper limit on earnings is constant in the sample (except for the limited variation arising from regional differences in prices). This also holds for $l_{2}$, so that all of the conditions are actually functions of the slopes and intercepts of the segments of the budget constraints. The maximum utility from semiretirement is, 
therefore, a function of $w, g+y$, and $u$. It follows, then, that

$$
P(W R)=h\left(w_{n}, g_{1}+y, w \cdot y+g\right) .
$$

We do not know what the functional form is, and one may not be derived without making assumptions about the form of the utility function and distribution of $u$. Instead of making these assumptions, we make the rather strong assumption that

$$
P(W R)=f\left(\alpha w_{n}+\beta\left(g_{t}+y\right)+\gamma w+\delta(g+y)\right) .
$$

In later work it would be desirable to relax the assumption that the argument of $f$ is linear in the variables. We choose $f$ to be the logistic function to bound the probability between zero and one.

We consider $w$ and $y$ to be exogenous; $w_{n}, g_{z}$ and $g$ are endogenous. $w_{n}$ is endogenous because the marginal income tax rate depends on tastes for work as does the probability of retirement. $g_{t}$ also depends on tastes for work through the marginal tax rate and through actual earnings. $g$ reflects past earnings, so that if there are persistent tastes for work, $g$ and current tastes for work will be correlated. In addition, $g$ is only observed for people who enter retirement or semiretirement. Consideration of the determinants of $t, g_{t}$ and $g$ will indicate how the structure may be identified.

The reduced forms for the marginal tax rate and for $g_{t}$ will depend in a nonlinear way on the wage rate and nonlabor income because of the nonlinearity of the tax schedule and because they are functions of income. We approximated these nonlinear functions by fourth-order polynomials in $w$ and third-order polynomials in nonlabor income. Benefits under social security depend on the 40 quarters of highest earnings. We have data on past earnings; however, we feel it is not appropriate to write the reduced form of benefits to be a function of past earnings due to varying and persistent tastes for work. That is, someone who worked a great deal in the past and would, therefore, tend to have high benefits, would also tend to work more today, and his probability of retirement would be low. This consideration led us to write the reduced form for benefits as a weighted average of polynomials of past wage rates and nonlabor income where the weights are the fraction of time spent at each wage rate.

If the probability of retirement were linear in the right-hand variables, two-stage least squares would yield consistent parameter estimates: the exogenous variables would be all the powers of the wage rate, non-labor income, other taxable income, and past wage rates, and the endogenous variables would be $w_{n}, g_{v}$, and $g$. Unfortunately, the linear probability model suffers from several inadequacies, the most important of which is that it does 
not confine the expected value of the probability to the interval between zero and one.

Hence, nonlinear estimation is required. In view of the endogeneity of several variables, nonlinear two stage least squares is a consistent estimator and hypothesis tests may proceed from the asymptotic normality of the estimator. $^{2}$

Let

$$
\widehat{\operatorname{Prob}(W R})_{i}=f\left(z_{i}^{\prime} \beta\right)+u_{i}
$$

where $f$ is the logistic function $\left(1 /\left(1+\mathrm{e}^{-z \beta}\right)\right)$ and $u_{i}$ are the residuals. Then this estimator minimizes

$$
S S R=\frac{1}{2} \hat{u}^{\prime} X\left(X^{\prime} X\right)^{-1} X^{\prime} \hat{u},
$$

where $X$ is our matrix of instrumental variables (i.e. powers of the wage, etc.).

A more precise description of the estimation method is given in the Appendix. In brief, we also account for the heteroscedasticity inherent in probability models by using a nonlinear two-stage generalized least squares estimator. The numerical calculations are performed using the DFP program of the Goldfeld-Quandt nonlinear optimization package.

The discussion of the estimation method referred to the probability of retirement from working. The probability of semiretirement from working depends on precisely the same variables, so we use the same specification and methods to estimate that probability equation.

\section{The data}

The data used in this study are taken from the Longitudinal Retirement History Survey, a panel study of households whose head (husbands, or single women) were 58-63 years of age in 1969. The households have been reinterviewed, insofar as possible, at two year intervals since then. However, the 1971 wave has only just been released; the 1973 and 1975 waves are still being processed. Hence, we are dealing with a data set on household heads in their early sixties. Since much retirement takes place at 65 and some even later, we must await the subsequent waves of the study to say more about the full age pattern of retirement.

In order to deal with a relatively homogenous sample and to avoid some measurement problems, we focus on 62-65 year old white males who were working in 1969, who were not receiving welfare, who answered the

\footnotetext{
${ }^{2}$ Both results derived in Amemiya (1974).
} 
questions relating to the variables of interest and who did not have a working wife. This winnowed the sample size to about 1,000 households, since we deleted households with working wives, husband not working, or nonwhite household head. We hope at a later stage to be able to say something about the retirement behavior of working women, but thought it best not to begin with the complications of multiple worker families. Further, as also reflected in the aggregate data reported in table 1 , about $15 \%$ of this group had already left the labor force by 1969 . Thus, persons with strong tastes for leisure and extremely serious health problems prior to this age bracket have been eliminated from the sample, and our results should be interpreted as conditional on working in 1969.

The key variables used in the study are defined as follows:

Gross wage (w): Hourly earnings before taxes.

Net wage $\left(w_{n}\right)$ : Hourly earnings after personal income and payroll taxes.

Social security benefit guarantee $(g)$ : The annual social security benefit for the household derived either from actual benefits (adjusted for any reduction) or from the benefit formula plus an estimate of average monthly covered earnings as described above.

Nonwage income: Interest, rent, dividends, etc, plus imputed income from other net assets. The actual tax paid and the marginal tax rate were constructed from data on the components of taxable income, exemptions, deductions, and the federal income tax tables.

Age: Dummy variables taking the value one for a specific age and zero otherwise, as indicated.

Health: A dummy variable taking the value one if respondent answered yes to one of several questions indicating a potential health limitation to work. Compulsory retirement: A dummy variable taking the value one if respondent worked at a job (in 1969) with a compulsory retirement program.

Family situation: Dummy variables taking the value one if no spouse was present and one if children were present, respectively.

Sample means and standard deviations for the variables of interest are presented in table 2 .

\section{Empirical results}

We turn now to our empirical results, estimation of probability of complete retirement and semiretirement equations and tests of hypotheses concerning the impact of social security upon early retirement. Recall, however, that these results are restricted to a very homogenous sample; at subsequent stages of our work, we will reaggregate to examine the differential impact of social security on different types of households and workers in 
Table 2

Sample means and standard deviations."

\begin{tabular}{lcc}
\hline Variable & Mean & Standard deviation \\
\hline Health & 0.19 & 0.39 \\
Compulsory retirement & 0.03 & 0.18 \\
No spouse present & 0.09 & 0.28 \\
Child present & 0.28 & 0.45 \\
Age $=62$ & 0.18 & 0.38 \\
Age $=65$ & 0.13 & 0.34 \\
Net wage & $\$ 3.36$ & 1.67 \\
Nonlabor income + tax grant & & \\
$\quad\left(\times 10^{3}\right)$ & $\$ 2.09$ & 3.24 \\
Nonlabor income + guarantee & & \\
$\quad\left(\times 10^{3}\right.$ ) & $\$ 5.74$ & 3.30 \\
Gross wage & $\$ 4.14$ & $\$ 2.52$ \\
Constant & 1.0 & - \\
Full retirement $=1$ & 0.12 & 0.32 \\
Semiretirement $=1$ & 0.09 & 0.28 \\
\hline
\end{tabular}

'For men age 60-65.

different occupations and industries. Also recall that the fifteen percent of white males not in the labor force are excluded from our sample, so we have probably excluded some workers with extremely poor health and others with greater than average tastes for leisure whose still earlier retirement may have been induced partially by the expectation of future social security benefits.

About twenty percent of those working in 1969 either retired or semiretired by 1971. Since in 1971 this group was aged 60-65, many more will obviously retire before they reach age 65 in subsequent years. With these provisos in mind, our empirical results are reported in tables 3 and 4. The

Table 3

Probability of retirement.

\begin{tabular}{|c|c|c|c|}
\hline Variable & Coefficient & Standard error & Change in probability \\
\hline Bad health & 0.95 & 0.25 & 0.097 \\
\hline \multicolumn{4}{|l|}{ Compulsory } \\
\hline retirement & 0.19 & 0.99 & 0.019 \\
\hline Single & 1.22 & 0.76 & 0.124 \\
\hline Wife and child & -0.37 & 0.92 & -0.038 \\
\hline Age 62 & -0.88 & 0.57 & -0.090 \\
\hline Age 65 & -0.03 & 0.71 & -0.003 \\
\hline \multicolumn{4}{|l|}{ Benefits } \\
\hline (thousands) & 0.82 & 0.37 & 0.083 \\
\hline Gross wage & -10.01 & 0.75 & -1.019 \\
\hline \multicolumn{4}{|l|}{ Nonlabor income } \\
\hline (thousands) & -0.69 & 0.45 & -0.070 \\
\hline Working wage & 12.01 & 0.76 & 1.222 \\
\hline Constant & -5.68 & 0.88 & - \\
\hline
\end{tabular}


Table 4

Probability of semiretirement.

\begin{tabular}{lclc}
\hline Variable & Coefficient & Standard error & Change in probability \\
\hline Bad health & 0.14 & 0.23 & 0.011 \\
$\begin{array}{l}\text { Compulsory } \\
\quad \text { retirement }\end{array}$ & 1.33 & 0.29 & 0.107 \\
Single & -0.21 & 0.37 & -0.017 \\
Wife and child & 0.32 & 0.23 & 0.026 \\
Age 62 & -0.53 & 0.21 & -0.043 \\
Age 65 & 0.67 & 0.18 & 0.054 \\
Benefits & & & -0.022 \\
$\quad$ (thousands) & -0.28 & 0.13 & -0.039 \\
Gross wage & -0.49 & 0.25 & 0.018 \\
Nonlabor income & & & 0.052 \\
$\quad$ thousands) & 0.22 & 0.13 & - \\
Working wage & 0.65 & 0.36 & 0.46 \\
Constant & -1.18 & & \\
\hline
\end{tabular}

first column of table 3 gives the results of estimating the coefficients of $P(W R)=1 /\left(1+\exp \left(Z^{\prime} \beta\right)\right)$, where the $Z$-vector includes the wage and social security benefits as discussed and also variables that describe the health, family composition and age of the individual. The second column gives the estimated asymptotic standard errors of the estimated coefficients. The rightmost column gives the probability change for a unit change in the $Z$-vector, $\partial P / \partial z_{i}=P(1-P) \hat{\beta}_{i}$. Table 4 gives the results for the probability of going from working to semiretirement.

The analysis above showed that we could identify the probabilities of moving among alternative segments of a kinked budget constraint by parameterizing those probabilities in terms of the slopes and intercepts of the segments, and that these in turn naturally related to powers of the wage, nonwage income, etc. Since some slopes and intercepts of the segments of the budget constraint are transformations of combinations of the basic parameters of the earnings test, there is no simple way to infer the effects of these parameters directly from a single coefficient. We are working on a program to simulate the effects on retirement of earnings test parameter changes.

Considering the difficulties in measuring some of the variables, in finding good explanatory variables for some of the right-hand endogenous variables, and in obtaining independent variation in some of the exogenous variables, the results are good: most of the estimated coefficients have the expected sign and are measured fairly precisely. The results on the probability of retirement are better than on semiretirement; this is not surprising because of the problems in measuring benefits of people who work.

The results for the probability of retirement are consistent with expectation in almost every case, and they generally indicate that the change in the 
budget constraint caused by the social security system has a considerable impact on retirement. But rather than discussing the magnitude of the coefficients, we shall concentrate on the change in the probability of retirement for a change in the variable. From the logistic probability equation that derivative is calculated as $P(1-P) *$ (estimated coefficient). In our data $P$ is 0.115 for retirement and 0.088 for semiretirement. Of course, for large changes in the variables, that derivative is not constant due to the nonlinear nature of the logistic function.

A worker who says that his health limits the amount or kind of work he is able to do has a considerably greater likelihood of retiring than a healthy worker: the probability almost doubles, going from 0.115 to $(0.115+0.097)$ $=0.212$. Clearly there is a considerable social cost of illness. Because the questions about health status were asked prior to retirement, the estimate is not likely to be the result of the self-selection that is found in some labor supply studies. If, in the estimation of labor supply functions, one uses, for example, the responses concerning health of nonworkers, the estimates may not be directly interpretable as the effect of health on retirement; it may simply reflect the systematic tendency of those who prefer to retire earlier to report that bad health is the reason for their not working.

If there is compulsory retirement at the workers' job, the probability of retirement increases by about two percentage points. This is not a very large change. The reason appears to be that many workers prefer to become semiretired, probably by changing jobs: the coefficient on compulsory retirement in the semiretirement equation implies an increase in the probability of semiretirement of 0.107 . This is mild evidence in favor of the hypothesis that substantial numbers of workers are forced to retire before they desire to retire. It would be interesting in future work to include interactions between the age dummies and the compulsory retirement dummy to discover if there are changes in work before compulsory retirement in anticipation of it.

Single men retire earlier in life than married men with wives, and the difference is substantial-about twelve percentage points. Apparently, when we hold the financial variables constant, we find that a wife increases the income requirements of the household, and, therefore, delays retirement of the husband. Similarly, the presence of a wife and child decreases the probability of retirement; but, because the husbands are 62-65 years old, the interpretation of this is not simple. A few of the offspring may be young: most are surely adults. Not surprisingly, the probability of (especially) semiretirement, rises with age.

The most interesting and easily interpretable coefficient of the financial variables are those for benefits and semiretirement, or gross, wage. Benefits is a measure of the income a worker would receive if he were to retire under social security, and it includes both nonlabor income from his assets and the 
social security benefits. The estimated coefficient is, therefore, directly interpretable as the retirement effect of changes in the benefit schedule. We see that the effects are substantial: a thousand dollar increase in benefits leads to an increase in the probability of retirement of about eight percentage points over the two years of the sample. This is a large increase, almost equal to our estimated probability of $0.115 .^{3}$

Increases in the gross wage lead to a large estimated decrease in complete retirement. Such an increase rotates segment $a$ upward and makes complete retirement less likely. The indicated change in probability is a point estimate at the observed probability, and would change substantially if the logistic function were evaluated for large changes in the gross wage. ${ }^{4}$

The nonlabor income variable represents the intercept of the pre-social security linearized budget constraint. The interpretation is that the introduction of social security benefits will have a smaller effect on the retirement behavior of people with high nonlabor income than on the behavior of people with low nonlabor income. In terms of the budget constraint diagram, fig. 1, we see that a high intercept of the linearized budget constraint means that the budget constraint will not be altered greatly by social security; therefore, our estimated negative coefficient is consistent with our expectations.

The working wage is: $(1-t) w$ where $t$ is the marginal tax rate. The estimated coefficient on working wage is not of the expected sign: an increase in the working wage rotates upward the linearized budget constraint. This would, as in the case of nonlabor income, make the part of the budget constraint due to social security less important, and hence one would expect to find fewer retirements among high wage workers than among low wage workers. Our result is surely due at least in part to the high collinearity

\footnotetext{
${ }^{3}$ As explained in the Appendix, the estimation was done in two rounds: in the first round, the right-hand endogenous variables including benefits were treated as if they were exogenous; in the second round, which gave the final results, they were considered to be endogenous. In the first round the coefficient on benefits was negative, indicating that people with large potential benefits tend to retire later than people with small benefits. This conforms to our prior beliefs that the variation in benefits is partly caused by variations in the tastes for work: someone who relatively prefers to work will have worked more, will have higher benefits, and will be less likely to retire than someone who prefers to work less. As far as we know, this is the first study to consider benefits to be endogenous, which may explain why some other studies have not been able to find a substantial impact of social security on retirement.

${ }^{4}$ The semiretirement wage coefficient is very collinear with the working wage: the estimated correlation is over 0.99. (Of course, the high collinearity is indicated by the large standard error.) In ordinary least squares estimation this only causes an increase in the variance of the estimates; the estimators are still unbiased and consistent. In this kind of nonlinear estimation, the estimators are consistent provided a global minimum of the objective function is found; however, high collinearity of the estimators of the different parameters makes it very difficult to find the global minimum with the numerical routines that are available. Even though our numerical routines indicate that a local minimum was found to a high level of accuracy. we prefer to interpret the result as indicating a substantial effect on retirement. but not be too insistent on the exact magnitude.
} 
between this estimate and that of the semiretirement wage. Another cause is the difficulty in measuring the working wage: the only difference between it and the semiretirement wage is the marginal income tax rate. We have used the standard tax tables to measure the tax rate; but, this is undoubtedly not completely accurate for this population, many of whom itemize deductions. ${ }^{5}$

The equation for probability of semiretirement does not give as many estimates that conform to expectations as the retirement equation. We think that this is primarily due to two problems in the data: first it is difficult to define semiretirement. Our definition requires both labor income and social security income in 1971. Clearly someone who retires fully part of the way through 1971 will improperly be classified as semiretired rather than retired. Further, since benefits are on a monthly basis, some persons may fully retire 'for a few months' then work full time for a while, etc. Second, the calculation of benefits is rather unsure for the semiretired: essentially we use the observed social security payments, labor earnings and the implicit social security tax rate to find what the benefits would be if the worker were to retire completely. Unfortunately, there is a great deal of error introduced by this process: for example, we cannot be sure we have found the correct segment of the budget constraint. Nevertheless, until the data are better, this seems to be the best that can be done.

The coefficients on the first four variables have the expected signs. The most interesting is that on compulsory retirement; as was mentioned above, many workers seem to be unwilling to retire completely if their jobs have compulsory retirement.

The coefficients on the four financial variables, while generally much smaller than the coefficients on the corresponding variables in the full retirement equation, have signs which are contrary to expectation. This is due both to the collinearity among these variables and the measurement problems mentioned above. When viewed simultaneously with the estimated coefficients from the complete retirement equation, the results clearly indicate a substantial net effect of social security on leaving full-time work for men in their early sixties. ${ }^{6}$ We conclude, however, that a more precise examination of semiretirement and its causes awaits more and better data. Fortunately,

\footnotetext{
${ }^{5}$ It is probably useful to point out that our considering the marginal income tax rate to be endogenous eliminates a problem found in some labor supply studies and which would explain the coefficient on the working wage. Had we used the observed marginal wage rate, high marginal wage rates would be associated with people with low tax rates who, therefore, worked less than average. If the variations in work are due to differences in tastes for leisure, we would expect those people to retire early; thus, we would find a positive correlation between the working wage and the probability of retirement caused by variations in tastes.

${ }^{6} \mathrm{We}$ obtained estimates of an equation for the probability of moving from working to either semiretirement or to retirement. These results are about the same as those of the semiretirement equation. Of course, the data have the same deficiencies as the data which were used in the semiretirement equation.
} 
subsequent waves of the Retirement History Survey should enable some averaging over variables and more precise measurement of semiretirement; further, these data will soon be merged with the individuals' social security earnings records, which should reduce the measurement error in social security benefits.

\section{Conclusion}

Our estimation procedure proves promising. While we could overcome some of the problems, e.g. collinearity between working and semiretirement wages, mentioned above if we imposed a particular utility or labor supply function on the data, we have been able to uncover a strong influence of social security on even early retirement. Some of the provisions clearly induce retirement; for others, the effects are more complex and depend upon the interaction of several aspects of the program.

In addition to examining a larger sample partitioned in different ways, we hope to extend our results in several directions. First, our estimates can be used to translate the probabiiity of retirement in the two-year period into probabilities of being retired by age 65 (which, of course, is a much larger probability).

Second, equations such as those reported above in principle can only be used to estimate the effect of changes in the parameters of the social security system, and hence the budget constraint of the worker, on the retirement probabilities of a worker with specified values of the variables. In order to calculate such effects on the total population, we must specify the multivariate frequency distribution of the elderly and integrate the effects over the ranges of these variables. Using typical or mean values can be misleading; for example, the average response can be quite different than the response at the average values.

Finally, we note the desirability of exploring more fully than we have been able to do thus far such potentially important areas of research as the heterogeneity in the population, ${ }^{7}$ the insurance aspects of social security and the demand for labor services of the elderly population.

\section{Appendix}

Let $y=1$ if an individual moves from working to retirement, and $y=0$ otherwise. We specify that if the budget constraint were exogenous

$$
P(y=1 \mid B)=\frac{1}{1+\mathrm{e}^{-B \beta}}=f(B \beta),
$$

where $B$ describes the exogenous budget constraint. However, we want to allow the budget constraint to be endogenous due to variations in tastes for

${ }^{7}$ See Hall and Heckman and Willis. 
work which will influence both social security benefits through past work habits and the marginal tax rate, and the probability of retirement. If the variables determining the observed budget constraint are $Z$, we specify that

$$
P(y=1 \mid Z)=\frac{1}{1+\mathrm{e}^{-Z \gamma}}=f(Z \gamma)=g(Z),
$$

where we expect that $\gamma$ will not be the same as $\beta$. We can write $y=f(Z \beta)$ $+u$. If $Z$ has the reduced form $Z=X \alpha+V$, one form of the nonlinear two-stage least squares estimator is the $\beta$ that minimizes $(y-f(Z \beta))^{\prime} X\left(X^{\prime} X\right)^{-1} X^{\prime}(y-$ $f(Z \beta))$. This estimator is consistent but not efficient because $u$ given $Z$ is not homoscedastic. In fact,

$$
E(u \mid Z)=(1-f(Z \beta)) g(Z)-f(Z \beta)(1-g(Z))=g(Z)-f(Z \beta),
$$

and

$$
\begin{aligned}
V(u \mid Z) & =(1-f(Z \beta))^{2} g(Z)+(f(Z \beta))^{2}(1-g(Z))-(g(Z)-f(B \beta))^{2} \\
& =g(Z)(1-g(Z)) \\
V(u \mid Z) & =\left[\begin{array}{ccc}
P_{1}\left(1-P_{1}\right) & \\
& P_{2}\left(1-P_{2}\right) & \\
0 & \ddots & P_{T}\left(1-P_{T}\right)
\end{array}\right]
\end{aligned}
$$

where $P_{i}=f\left(Z_{i}^{\prime} \gamma\right)$.

Therefore, we employ a two-step method: in the first step we estimate $\gamma$ from the logit equation $P(y=1 \mid Z)=f(Z \gamma)$. These are the estimates of the determinants of retirement taking the observed budget constraint to be exogenous. We then form

$$
\hat{V}(u \mid Z)=\left[\begin{array}{ccc}
P_{1}(\hat{\gamma})\left(1-P_{1}(\hat{\gamma})\right) & 0 \\
& P_{2}(\hat{\gamma})\left(1-P_{2}(\hat{\gamma})\right) & \ddots \\
0 & P_{T}(\hat{\gamma})\left(1-P_{T}(\hat{\gamma})\right)
\end{array}\right],
$$

where $P_{i}(\hat{\gamma})=f\left(Z_{i}^{\prime} \hat{\gamma}\right)$. On the second step we minimize in $\beta$,

$$
(y-f(Z \beta))^{\prime} \hat{S}^{-1} X\left(X^{\prime} X\right)^{-1} X^{\prime} \hat{S}^{-1}(y-f(Z \beta)),
$$

to yield $\widetilde{\beta}$, where $\hat{V}(u \mid Z)=\hat{S}^{\prime} \hat{S}$.

This amounts to weighting each observation by $1 / \sqrt{ }[\hat{P}(1-\hat{P})]$. 


\section{References}

Amemiya, Takeshi, 1974, The nonlinear two stage least squares estimator, Journal of Econometrics, February.

Boskin, Michael, 1977, Social security and retirement decisions, Economic Inquiry, January.

Feldstein, M., 1974, Social security and private capital accumulation: International evidence in an extended life-cycle model, Harvard Institute of Economic Research Discussion Paper, Harvard University, Cambridge. Massachusetts.

Hall, R., 1975, An analysis of the labor supply results, in: M. Timpane, ed., An evaluation of the New Jersey-Pennsylvania negative income tax experiment (The Brookings Institution, Washington. D.C.).

Heckman, J. and R. Willis, 1975, A beta-logistic model of sequential labor force participation, Journal of Political Economy.

Kendall, Maurice G. and Alan Stuart, 1963-68, The advanced theory of statistics, 2nd ed. (3 vol.) (Hafner, New York).

Kurz, M. et al., 1974, Experimental determination of time preference rates, SRI memo.

Pechman, Joseph A., Henry J. Aaron and Michael K. Taussig, 1968, Social security: Perspective for reform (The Brookings Institution, Washington, D.C.).

Steiner, Peter and Robert Dorfman, 1959, The economic status of the aged (University of California Press, Berkeley). 